\title{
EDUCAÇÃO MENOR E AGENCIAMENTOS E INTERSECÇÕES E ACONTECIMENTOS E DESEJOS E APRENDIZAGENS E...
}

\section{EDUCACIÓN MENOR Y AGENCIAMIENTOS Y INTERSECCIONES Y EVENTOS Y DESEOS Y APRENDIZAJES Y...}

\author{
Elder José de Oliveira ${ }^{1}$
}

\begin{abstract}
Resumo: A presente pesquisa busca investigar os agenciamentos entre desejo e aprendizagem. Para tanto, vislumbramos a possibilidade de pensar a partir do conceito de minoridade no pensamento criado por Deleuze e Guattari (2017) e deslocado para o campo da educação por Gallo (2002). Entendendo educação menor como resistência, luta constante contra as formas da máquina capitalista que estriam espaço e tempo até o sufocamento das maneiras de vida, acreditamos que tal incursão apresenta relevância ao buscarmos movimentar ideias na produção de novas possibilidades de ser, ensinar e aprender. No trajeto, traçamos alianças com Sílvio Gallo, Virgínia Kastrup, Gilles Deleuze e Félix Guattari, defendendo a tese da aprendizagem como afirmação da vida potente, alegre, criativa - em oposição à vida maior, triste, organizada pela molaridade capitalista.
\end{abstract}

Palavras-chave: Desejo; aprendizagem; Educação Menor.

Resumen: Esta investigación busca investigar los vínculos entre el deseo y el aprendizaje. Para tanto, vislumbramos la posibilidad de pensar desde el concepto de minoría en pensamiento creado por Deleuze e Guattari (2017) y desplazado para el campo de educación menor Gallo (2002). Entendiendo educación menor como resistencia, lucha constante contra las formas de la máquina capitalista que estrían espacio y tiempo hasta el sofocamiento de las maneras de vida, creemos que tal incursión expone relevancia cuando buscamos mover las ideas de nuevas posibilidades de ser, enseñar y aprender. En la ruta, hicimos alianzas con Sílvio Gallo, Virgínia Kastrup, Gilles Deleuze e Félix Guattari, defendiendo la tesis de aprendizaje como una afirmación de la vida potente, alegre, creativa - en oposición a la vida mayor, triste, organizada por la molaridad capitalista.

Palabras-clave: Deseo; aprendizaje; Educación Menor.

Amar e mudar as coisas me interessa mais.

Belchior

Como entrar nesse trabalho? Existe alguma porta ou caminho certo? Escrita em experimentos, movida por emoções, sensações, vontades, desejos. Com Ribeiro (2016) vemos a possibilidade de operar com um método em experimentação, aberto aos fluxos e devires imanentes a pesquisa, então o escolhemos aqui, pois, acreditamos que nos propicia aberturas para o novo. Experimentações que não existe uma lógica racional em si, mas que acontece através de encontros e desencontros. Uma vez que nosso tema é aprendizagem, algumas questões são pertinentes. Afinal, o que é aprender? Como alguém aprende? Quando alguém aprende? Quem aprende? Onde aprende? Em quais circunstâncias aprende?

Visto a pluralidade de pesquisas sobre a área da aprendizagem, anunciamos de antemão que faremos pelas vias da filosofia da diferença, com destaque para o pensamento de Deleuze e Guattari, Silvio Gallo e Virginia Kastrup. Para Gallo (2002), um dos riscos de pensar a aprendizagem é recair no âmbito de educação maior, um modo de ensino que delimita o que

\footnotetext{
${ }^{1}$ Graduando em licenciatura do curso de Educação Física na FEFISO, membro do grupo de estudos GEPEFFEFISO, e é iniciante científico pelo PBIC-FEFISO.E-mail: elderjoliveira99@gmail.com.
} 
fazer e nos diz como fazer, que possui relações com as macropolíticas, políticas de parâmetros cerrados, diretrizes aprisionantes.

Em contramão, lançamos à experimentação pensar através do conceito de educação menor, deslocado por Gallo (2002) da obra Kafka: por uma literatura menor, de Gilles Deleuze e Félix Guattari (2017), que se inspiram em Franz Kafka (1883 - 1924), um judeu tcheco que escreveu em alemão por conta da predominância cultural em sua região. Porém, escreveu um alemão marginal, das ruas, do gueto, das favelas, subvertendo a tradição da língua maior. Deleuze e Guattari, criam três características para pensar em uma literatura menor, sendo elas: desterritorialização da língua, ramificação política e valor coletivo. Com isso, vemos uma maior abertura e potencial, uma brecha, espaços para pensarmos as intersecções entre o desejo, aprendizagem e vida. A educação menor, pensada nas mesmas características de uma literatura menor, é uma prática produzida no âmbito da micropolítica, no cotidiano, em aulas, no dia-a-dia, diferente das macropolíticas produzidas nos gabinetes. Gallo (2017, p. 70) nos propõe em produzir "educação menor como máquina de resistência". Podemos questionar a importância de pensar uma educação menor como resistência afinal resistência contra o quê? Entendemos a resistência da educação menor como luta ao fascismo, aos modos de vida que estriam a vida, que nos matam em vida, a maquinaria capitalista.

Caminhando a outro platô, que não se separa do qual citamos acima, mas que se dá através de outros meios, também nos apoiamos em Kastrup (2007) para entender o processo de aprendizagem. Para Kastrup, a aprendizagem se dá em dois modos, sendo eles: aprender recognitivo e aprendizagem inventiva. A recognição é a ideia de reconhecer algo, remete ao idealismo platônico. Por exemplo, a técnica em alguma prática corporal, repetida exaustivamente, fazer como, reproduzir o esperado, estruturado, fixado, congelado, sedentarizado. Com isso, vemos a grande força da técnica e da memória, pois ela é um modo de repetir o idêntico, e a escola é a instituição moderna que faz isso por excelência, negando os saberes dos discentes e reproduzindo uma educação bancária (FREIRE, 1987).

O conceito de aprendizagem inventiva Kastrup (2007), também embasado no âmbito das filosofias da diferença, defende que aprender é construir um mundo passa si, e em conjunto se constrói. Aprendemos com e a partir de problemas que nos afetam, nos levam a pensar, motor do pensamento. Deste modo, Kastrup (2007) aponta a partir de Deleuze que o problema é o motor do pensamento, pois o pensamento não é algo natural, ora pensamos porque somos forçados a pensar, quando encontramos com algum problema. Assim, Kastrup (2007) defende que devemos ter direito aos nossos próprios problemas e também criar nossos próprios problemas. Ora, pensando isso no espaço da Educação maior nos deparamos com problemas de outras pessoas, eles já estão dados, estruturados, já foram pensados e possui uma única resposta correta.

Kastrup (2007) mergulha em Bergson, para pensar o tempo e aprendizagem, vemos que diferença entre eles, tempo cronológico e tempo duração, vivido. O primeiro diz respeito sobre o tempo contável, a sucessão do tempo, ou seja, podemos contar os segundo, minutos, horas, dias, semanas, messes, anos... tempo estruturado. As grandes teorias da aprendizagem estão ancoradas nessa perspectiva de tempo. E o tempo intensivo, em devir, que segue a via dos fluxos, um momento em que não nos damos conta da passagem do tempo, podemos entende-lo como qualitativo. Com Deleuze e Guattari (2011) podemos entender o tempo cronológico sendo estriado, e o tempo vivido como liso. Por essa via, notamos algumas características da aprendizagem inventiva e recognitiva.

Ainda com Kastrup (2007) ela nos ajuda a pensar entre a inteligência e intuição, a partir de Bergson ela desloca para aprendizagem. A inteligência em Kastrup, é entendida como a capacidade de reconhecer algo, entender, memorizar e reproduzir, caracterizado pela excessiva repetição, um aprender bastante voltado à razão. E a intuição é da ordem do sentido, da sensibilidade, dos afetos, caminhando com o tempo bergsoniano, o tempo do devir, da passagem, do instante. A inteligência se debruça em resolver problemas, enquanto a partir da intuição a ideia é mover, criar problemas. 
Assim a aprendizagem recognitiva é caracterizada pela representação (imagem), tempo cronológico e inteligência, e a aprendizagem inventiva em pensar o encontro, sempre no entre, se dando através do pensamento sem imagem, tempo durativo e intuição.

Poderíamos pensar em uma dialética? Um embate entre forças? Recognição versus invenção? Não! Uma vez que aprendemos com Deleuze, que um rizoma não possui uma linearidade, uma sequência lógica, dada a priori, estruturada de antemão, rizoma se dá em um movimento transversal, que ao se encontrar com algo, possui o potencial de ramificar, conectarse com outras coisas. O rizoma tem alguns princípios, sendo eles: "princípio de conexão; princípio de heterogeneidade; princípio de multiplicidade; princípio ruptura assignificante; princípio de cartografia; princípio de decalcomania" (GALLO, 2017, p. 76-78). Logo, escapa de modos arborescentes, a lógica binária do "ou", isso ou aquilo, verdadeiro ou falso, bem ou mal. Distante disso, o potencial de um rizoma é afirmar as multiplicidades $e$ conjunções $e$ diferenciações $e$ adições $e . .$. e... e... tendo o intuito de pensar a partir de Nietzsche que as coisas estão para além do bem e do mal (DELEUZE, 2018).

Com Nodari e Corazza (2019, p. 6) notamos que "a invenção é o produto de uma tensão constante entre duas tendências: a da criação e a da repetição. A criação não é rara ou fruto do acaso, mas exige esforço para que seja ultrapassada a tendência repetitiva". Ou seja, as coisas não estão por aí perdidas para serem descobertas ou encontradas, mas sim criadas, inventadas, com árduo trabalho, demanda suor, gastar tempo. Notamos aqui a importância da repetição. Contudo, a crítica não é para a repetição em si, mas, em seu uso demasiado

Por esses movimentos, entendemos que esse trabalho culmina em uma escrita-rizoma, uma escrita rizomática que advém de resultados, efeitos. Kastrup (2007) inspirada em Deleuze, bem nos lembra que, não invenção sem repetição, e não há repetição são invenção, eles coexistem, acontecem juntos, com mais ou menos intensidade. Deleuze (2018) muito bem nos ensina que é o que retorna é sempre a diferença, um eterno retorno do mesmo na diferença. Tendo em vista isso, que a escola é formada por linhas molares, e isso dobra a atuação dos professores/as, não negamos isso, o engessamento, mas nossa aposta aqui é em outras linhas, linhas de vida, linhas alegres, linhas potentes, linhas moleculares, linhas de fuga, uma aposta por vida, pela vida.

\section{Linhas, desejo, agenciamento e criação...}

A gente precisar ter uma educação voltada para a vida, pois é para isso que a gente aprende, para viver melhor

Rubem Alves

Tendo em vista que as professoras e professores são atravessados essas linhas, em sua maioria linhas fixas, duras como apresentado acima, nos grandes documentos. Como poderíamos borrar essa linha? Pensamos que o professor, em meio essas relações de poder, esses duplos agenciamentos, desempenham uma atuação fulcral e podem priorizar alguma concepção, dando mais vazão ou vetando desejos, criando aberturas, brechas, experimentações, agenciando encontros. Compondo com isso, o Transversal $(2015$, p. 66) cria o conceito de pedagogo celibatário, que " a função deste Pedagogo não é de preocupar-se com a relação hifenizada ensino-aprendizagem, mas de se deixar afetar por algo que lhe escapa, provocando e realizando uma retropotencialização em relação àquilo que o tira de seu lugar de certeza".

Rumando pelas veredas rizomáticas, de uma escrita em experimentação, com Virgínia Kastrup, vemos que: 
O professor é um atrator, embora o atrator não seja necessariamente um professor. $\mathrm{O}$ atrator é uma função: define-se por seu poder de atrair, de arrastar consigo. Um companheiro pode desempenhar esta função, ou a própria matéria para os autodidatas. No caso de haver um professor, ele atrai para a matéria, e não para um saber pronto. Ele é alguém que exerce a função de conduzir o processo, a expedição a um mundo desconhecido, de fazer acontecer o contato, de possibilitar a intimidade, de acompanhar, e mesmo de arrastar consigo, de puxar. Não para junto de si, mas para junto da matéria, para o devir da matéria, seguindo, acompanhando sua fluidez (KASTRUP, 2001, p. 26).

Podemos entender que o professor é agenciador de encontros, na educação, algo como preparar uma festa, tem uma série de detalhes para pensar a priori, como enfeites, comida, quem chamar, qual música tocar etc., mas, somente no encontro saberemos se será uma festa, pois, depende do uso que faremos, é uma demanda que segue a via de mão dupla. O que nos abre espaço para falarmos sobre agenciamentos, desejo e suas linhas, pensando a partir de Deleuze e Guattari $(2011 ; 2012 ; 2017)$.

Para Deleuze e Guattari (2011, p. 11) tudo é máquina, e afirmam no livro $O$ anti-Édipo "há tão somente máquinas em toda parte, e sem qualquer metáfora: máquinas de máquinas, com seus acoplamentos, suas conexões. Uma máquina-órgão é conectada a uma máquina-fonte: esta emite um fluxo que a outra corta". O que nos diferencia das outras máquinas, é que somos máquinas desejantes, pois temos vontades, quereres, sentimentos, desejos. Deleuze e Guattari (2011) colocam que podemos entender o desejo através de duas maneiras, sendo elas, pela falta ou produção, para ambos o desejo é sempre produtivo, desejo esquizo, desejo por vida, com isso, fazem uma diferenciação da psicanalise que entende o desejo como falta, fantasma, vazio, a partir do complexo de Édipo, eles, defendem que nada falta no desejo, tudo é produção, produção desejante.

O desejo e nossas relações, de acordo com Deleuze e Guattari (2012) são compostos por três grandes linhas, sendo elas: linhas duras ou molares, linhas maleáveis ou molecular e linhas de fuga. Nas linhas duras, tudo parece contável, previsto e controlável, passagem de um ponto a outro, vemos "nossa vida é feita assim: não apenas os grandes conjuntos molares (Estados, instituições, classes), mas as pessoas como elementos de um conjunto, [...] para garantir e controlar a identidade de cada instância, incluindo-se aí a identidade pessoal" (DELEUZE; GUATTARI, 2012, p. 73).

Linhas fixas, engessadas, sedentarizadas, congeladas, linhas de controle, linhas de um por vir, que nega o presente para viver em um futuro incerto. Os exemplos são vários, elencamos alguns aqui: sair do ensino médio, entrar na faculdade, arrumar um estágio, terminar a faculdade, arrumar um emprego, casar, comprar um carro, ter filhos... tal linha que faz relação com o tempo cronológico abordado por Bergson (apud KASTRUP, 2007). Caracterizada pelo desejo em falta, uma vida em por vir, negando o hoje, o agora, o presente.

Todavia, Deleuze e Guattari (2012, p. 74) bem nos ensina que essa linha “comporta até mesmo muita ternura e amor. Seria fácil demais dizer: 'essa linha é ruim', pois vocês a encontrarão por toda parte, e em todas as outras". A segunda linha do desejo é a linha molecular, linha flexível, maleável, essa é linha da experimentação, linha do devir que se opõe ao porvir, onde há as produções dos afectos intensivos do desejo, entretanto Deleuze e Guattari (2012, p. 75) colocam que "não se dirá que ela seja necessariamente melhor". A terceira linha do desejo é a linha de fuga, é a linha de desterritorialização absoluta, abstrata, de criação, ruptura, que marca a explosão das outras duas. Deleuze e Guattari (2012, p. 77) bom nos lembra que "as três linhas não param de se misturar" adiante, ainda com Deleuze e Guattari (2012, p. 83) vemos que as "linhas que nos compõe, diríamos três espécies de linhas. Ou, antes, conjuntos de linhas, pois cada espécie é múltipla. Podemos nos interessar por um dessas linhas mais do que outras, e talvez, com efeito, haja uma que seja, não determinante, mas que impor mais do que outras...”. 
Deste modo, estamos entendendo o desejo a partir dessas três linhas, vemos com que essas relações se dão através de agenciamentos, ou seja, não desejamos por que queremos, e sim porque somos agenciados, influenciados a querer algo, uma dobra da fora no dentro. Deleuze e Guattari (2017, p. 147) apontam que o agenciamento tem "duas faces: é agenciamento coletivo de enunciação, é agenciamento coletivo do desejo", e nesse plano, conseguimos conectar com a aprendizagem, fazendo uma ressalva que, o capitalismo atravessa e corta todas essas relações, ele estria o tempo por excelência, já a via do desejo esquizo, vemos como pequenos instantes de espaços lisos, alegres. Poderíamos pensar em uma educação que as vontades, os desejos dos alunos e alunas sejam levados em consideração? Um momento potente, que priorize espaços lisos, que suscite linhas maleáveis.

Sobre as relações entre desejo e aprendizagem, vemos com Schérer, que podemos entender como uma associação de paixões, vejamos:

Como aprender a gramática e fazer com que ela seja amada por uma jovem que ama o alho? pergunta-se ele em uma passagem consagrada à educação baseada na harmonia (Fourier, 1966-7, p. 257). "Esta jovem gosta de alho e não gosta de estudar a gramática". Então, como fazer com que ela a aprenda? Enxertar a gramática nessa paixão primeira, colocando-a em um grupo industrial de "alhistas". E, ao apresentar-se-lhe uma "Ode ao alho", ela se apressará a lê-la e, pouco a pouco, será conduzida ao estudo da poesia lírica e da gramática. Historinha cômica, sem dúvida, mas plena de sentido, do sentido da vida e não da metodologia abstrata. E é preciso ampliar esse tipo de experiência, por meio de outras relações passionais e atrativas, que são os verdadeiros acompanhamentos ou as verdadeiras arrancadas do aprender (SCHÉRER, 2005, p. 1191).

Tendo em vista essa passagem de René Schérer, vemos uma possibilidade de pensar as relações entre desejo e aprendizagem, através de uma educação menor, como Gallo (2017, p. 68) propõe "fazer educação menor como máquina de guerra". Apostamos no potencial que os professores e professoras possuem em fazer microrrevoluções em seus cotidianos, no dia-a-dia escolar.

O que pode um(a) professor(a) agregar, que suspenda o movimento mecânico do fazer? A proposta é interromper a ação repetitiva dos fazeres educacionais, imprimir inventividade ao currículo, desenhando-o em rizomáticos contornos, ao mesmo tempo em que se estabelece rigor conceitual, escapando dos exercícios de fixação de conteúdos, tão caros aos sistemas de ensino, que investem pesado no modelo competitivo -, para buscar, experienciar saberes. Des-pedagogizar a educação hiper-escolarizada (TRANSVERSAL, 2015, p. 16).

E realizamos tais apostas dada a evidente exaustão da escola moderna e suas formas tradicionais. São denúncias que partem por todos os lados, sejam construção acadêmicas ou não. Por exemplo, no filme, Sociedade dos poetas mortos (1989) que se passa em uma escola tradicional no ensino médio, nos em 1959 nos Estados Unidos, vemos uma educação hiperescolarizada, balizada em linhas duras, linha do por vir, e o processo de decodificação, do entendimento, da moralização, de repetição é excessiva, mesmo nesses espaços há possibilidades de criação, de desvios, fugas. No desenho Irmão do Jorel (2014), especificamente no segundo episódio, gangorras da revolução, vemos algumas possibilidades de criação de brechas para minorar, para resistir. Com as músicas do rapper compositor Emicida (entre tantos outros) vemos o potencial de minorar, de fazer o maior gaguejar, produzir outras formas de afetos, apostando na sensibilidade, nos afetos, na arte. Com a poesia de Rubel vemos 
"a vida é boa quando se brinca demais quando se canta e não se olha para trás", um convite a vida, para viver o hoje, brincar com a vida, dançar com ela.

A aprendizagem é atravessa por todos os processos que citamos enquanto invenção têm relações com as potências dos encontros, ela enquanto acontecimento se dá em relações a imanência dos problemas, problemas aqui não para ser solucionados, com uma resposta única, mas, sim como Kastrup (2007) os coloca, para serem inventados, e ainda não enquanto um problema na ordem do racional, e sim para ser sentido.

Pela imanência dos acontecimentos, outro ponto que alimenta este trabalho é a ideia que Bergson (apud KASTRUP, 2007) de inteligência e intuição, Kastrup entende a inteligência com a capacidade de resolver problema, um problema já dado, e ao desenvolver técnicas é possível ser respondido em um menor tempo e com melhor precisão. A intuição, diferente desta lógica racional da inteligência, é movida pelos afectos, pela sensibilidade que é sempre singular, isto é, vemos pela intuição um problema sensível, onde se faz um convite para criar, inventar, pensar diferente. No intento de em outros modos, experimentar outros encontros, estamos fazendo circular outros enunciados e desejos, defendendo que o aprender pode, mas não precisar ser sempre um movimento chato, triste, despotencializado, fraco. Entendemos com Gallo (2017, p. 84) que a metáfora de "lançar sementes" pois, no processo de aprendizagem não há garantias a priori, do que é aprendido. Seria possível pensar entre um ensino (aulas) sem garantias concretas de aprendizagem? Pensando a aprendizagem em um sentido qualitativo, que Nietzsche coloca e não quantitativo, representacional, contável, como vemos nas provas tradicionais (DELEUZE, 2018).

Vemos com Bergson (apud KASTRUP, 2007) uma possibilidade de intuir, claro que, cada pessoa tem seu tempo singular, talvez, as coisas façam sentido após anos, dias, meses, e talvez não faça. Mas, pensando em aulas enquanto acontecimento, podemos intuir o que pode elevar a potência do encontro. Neste emaranhado de linhas e sentidos, defendemos uma aprendizagem em conexões, em agenciamentos com o desejo e, sendo uma forma de afirmar a vida. Pois, é preciso experimentar com um corpo para saber o que ele pode (NODARI e CORAZZA, 2019, p. 8).

\section{Algumas palavras finais}

Nesta breve incursão do pensamento, o intento foi de pensar a partir da educação menor possibilidades de borrar o maior, de tencionar as linhas molares, colocar movimento no que está sedentarizado, apostando na potência das linhas flexíveis e de fuga. E com isso, podemos pensar nos agenciamentos entre desejo e aprendizagem, uma educação rizomática, uma atração de paixões. Eis a grande potência de uma educação menor rizomática, feito de conjunções inacabáveis, pensar no entre recognição $e$ invenção $e$ inteligência $e$ intuição $e$ tempo cronológico $e$ durativo $e$ linhas $e$ desejos $e \ldots e \ldots e \ldots$ Defendemos assim, uma educação que leve a vida em consideração, crie momentos de alegria, de produção de potência, de singularização, embate contra os tipos de fascismo e que possamos afirmar a vida. Assim, apostamos no micro, no molecular, no processo de minorar, na atuação de um professor-conector, celibatário que imerso aos agenciamentos escolares, possui potencial para fazer microrrevoluções do desejo.

\section{Referências}

DELEUZE, Gilles; GUATTARI, Félix. $O$ anti-Édipo: capitalismo e esquizofrenia, vol. 1. Trad. Luiz B. L. Orlandi. São Paulo: Editora 34, 2011. 
DELEUZE, Gilles; GUATTARI, Félix. Mil platôs: capitalismo e esquizofrenia, vol. 3. Trad. Aurélio G. Neto, Ana Lúcia de Oliveira, Lúcia Cláudia Leão e Suely Rolnik. 2. ed. São Paulo: Editora 34, 2012.

DELEUZE, Gilles; GUATTARI, Félix. Kafka: por uma literatura menor. 1. ed. 3. reimp. Belo Horizonte: Autêntica Editora, 2017.

DELEUZE, Gilles. Nietzsche e a filosofia. Trad. Mariana de T. Barbosa, Ovídio de A. Filho. São Paulo: n-1 edições, 2018.

FREIRE, Paulo. Pedagogia do oprimido. 17. ed. Rio de Janeiro: Paz e Terra, 1987.

GALLO, Silvio. Em torno de uma educação menor. Educação e Realidade, v. 27, n. 2, p. 169178, jul./dez. 2002.

GALLO, Silvio. Deleuze \& educação. 3. ed. 2. reimp. Belo Horizonte: Autêntica Editora, 2017.

IRMÃO do Jorel. Produção de Juliano Henrique. Vitória - ES, Brasil: Cartoon Network, 2014.

KASTRUP, V. Aprendizagem, arte e invenção. Psicologia em Estudo, Maringá, PR, n. 1, p. 17-27, jan./jun. 2001

KASTRUP, Virgínia. A invenção de si e do mundo: uma introdução do tempo e do coletivo no estudo da cognição. Belo Horizonte: Autêntica, 2007.

NODARI, Karen Elisabete Rosa; CORAZZA, Sandra Mara. Procedimentos didáticos de invenção: a potência dos signos das artes. Educ. Perspect., Viçosa, MG, v. 10, p. 1-13, 2019.

RIBEIRO, Cintya Regina. O agenciamento Deleuze-Guattari: considerações sobre método de pesquisa e formação de pesquisadores em educação. Educação Unisinos, v. 20, n. 1, p. 68-75, jan.-abr., 2016.

SCHÉRER, René. Aprender com Deleuze. Educ. Soc., Campinas, v. 26, n. 93, p. 1183-1194, set./dez. 2005.

SOCIEDADE dos poetas mortos. Direção de Peter Weir. Estados Unidos: Walt Disney Studios, 1989. 1 DVD.

TRANSVERSAL, Grupo. Educação menor: conceitos e experimentações. 2. ed. Curitiba: Appris, 2015. 